\title{
Moderate rest intervals are superior to short intervals for improving PAI-1 following exhaustive exercise in recreational weightlifters
}

\author{
Fabrício Eduardo Rossi', Jose Gerosa-Neto', Tiego Aparecido Diniz² ${ }^{2}$ Ismael F. Freitas Junior ${ }^{3}$,Fabio Santos Lira ${ }^{1, *}$ \\ Jason Michael Cholewa ${ }^{4}$ \\ 'Exercise and Immunometabolism Research Group, Department of Physical Education, Universidade Estadual Paulista (UNESP), Presidente Prudente, Brazil \\ ${ }^{2}$ Department of Cell and Developmental Biology - Institute of Biomedical Sciences, University of São Paulo, São Paulo, Brazil \\ ${ }^{3}$ Department of Physical Education, Universidade Estadual Paulista (UNESP), Presidente Prudente, Brazil \\ ${ }^{4}$ Department of Kinesiology, Recreation, and Sport Studies, Coastal Carolina University, Conway, SC, USA
}

This study investigated the influence of short and moderate recovery intervals on lipid profiles and plasminogen activator inhibitor-1 (PAI-1) following exhaustive strength exercise in recreational weightlifters. Seven subjects performed two conditions in a randomized order: short, $90 \%$ of one maximum repetition (1RM) and 30 -sec rest allowed between sets; moderate, $90 \%$ of $1 \mathrm{RM}$ and 90 -sec rest allowed between sets. Total cholesterol (Chol), high-density lipoprotein cholesterol (HDL-c), low-density lipoprotein cholesterol (LDL-c), triacylglycerol (TAG), Chol/HDL-c ratio and PAI-1 concentrations were assessed at baseline, immediately postexercise, and 15- and 30-min postexercise (post-15 and post-30). The LDL-c concentrations decreased and HDL-c concentrations increased in both conditions but without significant differences (LDL-c: 30 sec: pre, $82.0 \pm 19.5 \mathrm{mg} / \mathrm{dL}$, immediately, $73.9 \pm 16.4 \mathrm{mg} / \mathrm{dL}, 90 \mathrm{sec}$ : pre, $75.9 \pm 30.8 \mathrm{mg} / \mathrm{dL}$, immediately, $66.2 \pm 35.5 \mathrm{mg} / \mathrm{dL}, P=0.423 ; \mathrm{HDL}-\mathrm{c}: 30 \mathrm{sec}$ : pre, $53.5 \pm 9.2 \mathrm{mg} / \mathrm{dL}$, immediately, $61.4 \pm 11.4 \mathrm{mg} / \mathrm{dL} ; 90 \mathrm{sec}$ : pre, $55.8 \pm 11.1 \mathrm{mg} / \mathrm{dL}$, immediately, $84.9 \pm 27.8, \mathrm{mg} / \mathrm{dL} ; P=0.146)$. On the other hand, PAI-1 had a tendency to decrease only in the 90 -sec condition (pre, 7,754.9 $\pm 2,927.7 \mathrm{pg} / \mathrm{mL}$; immediately, 5,313.1 $\pm 4,637.4 \mathrm{pg} / \mathrm{mL}$; $P=0.085)$. There was a positive correlation between PAI-1 and Chol ( 30 sec: $r=0.83$, 90 sec: $r=0.91 ; P<0.05)$, PAl-1 and fat-free mass in both conditions (30 sec post-15: $r=0.79$, post-30: $r=081, P<0.05$; 90 sec immediately: $r=0.77$, post-15: $r=0.81 ; P<0.05)$, and PAl- 1 and TAG only in 30 $\sec (r=0.87, P<0.05)$. Short and moderate intervals of recovery improve lipid profiles after heavy strength exercise but only $90 \mathrm{sec}$ induced greater improved in PAI-1 concentration in recreational weightlifters.

Keywords: Strength exercise, Interval of recovery, Fibrinolysis

\section{INTRODUCTION}

Physical inactivity can result in decreased fat-free mass (FFM), increased total fat mass (FM) and trunk fat, and contributes to the development of morbidities such as dyslipidemia (high levels of low-density lipoprotein cholesterol [LDL-c] and low high-density lipoprotein cholesterol [HDL-c]) and metabolic syndrome (Kueht et al., 2009). Additionally, lack of physical activity favors changes in blood coagulation and fibrinolysis, and increases the risk of car- diovascular diseases such as atherosclerosis, which is the leading cause of death worldwide (Rosamond et al., 2008). On the other hand, physical activity or exercise training that improves cardiovascular fitness has been shown to improve lipid profile and blood fibrinolysis (Tambalis et al., 2009).

Plasminogen activator inhibitor-1 (PAI-1) is a major inhibitor of fibrinolysis that increases the risk of ischemic cardiovascular events (Vaughan, 2005) and is elevated in sedentary subjects compared to trained athletes (Lira et al., 2010a). Several studies have
${ }^{*}$ Corresponding author: Fabio Santos Lira (D) http://orcid.org/0000-0002-9645-1003 Department of Physical Education, Universidade Estadual Paulista (UNESP), Roberto Simonsen Street, nº 305 - Educacional center, 19060-900, Presidente Prudente, Brazil

Tel: +55-18-3229-5826; Fax: +55-18-3229-5388, E-mail: fabiolira@fct.unesp.br Received: September 27, 2016 / Accepted: December 10, 2016
This is an Open Access article distributed under the terms of the Creative Commons Attribution Non-Commercial License (http://creativecommons.org/licenses/by-nc/4.0/) which permits unrestricted non-commercial use, distribution, and reproduction in any medium, provided the original work is properly cited. 
shown significant benefits in lipid profile, coagulation and fibrinolytic responses, primarily after moderate and maximal aerobic exercise protocols (Kelley and Kelley, 2006; Ouerghi et al., 2014), but also in response to strength exercise (Nagelkirk et al., 2010). Ahmadizad and El-Sayed (2003) compared low- versus high-volume resistance training with a control group and reported greater reductions in PAI-1 with higher volume resistance training after 5 sets of 9 exercises in healthy subjects. Nagelkirk et al. (2010) performed 6 sets of 10 repetitions on leg extension with $70 \%$ of one maximum repetition $(1 \mathrm{RM})$ and 120 sec of recovery intervals in healthy women with age between $18-28$ years old and observed an increase in tissue plasminogen activator (tPA) but no difference in PAI-1 or markers of coagulation. Additionally, body fat percentage was negatively correlated to the tPA response to exercise $(r=-0.44)$, and positively related to PAI-1 at baseline $(r=0.47)$ and postexercise $(r=0.47)$.

It is well-known that strength training has anticatabolic effects and can improve skeletal muscle carbohydrate metabolism (Lira et al., 2014), while changes in fat utilization depends on a dose-response relationship to the volume of resistance exercise (Shannon et al., 2005). Thus, when a higher volume of exercise is performed there is a higher lipoprotein lipase activity and energy expenditures that improve lipid profiles PAI-1. Several studies have shown that an acute bout of intense exercise can induce a significant activation of fibrinolysis (Ahmadizad and El-Sayed, 2003; Baynard et al., 2007; deJong et al., 2006; Kupchak et al., 2013; Nagelkirk et al., 2010), likely mediated by the release of tPA from the vascular endothelial cells. tPA concentrations in response to resistance exercise appear to be volume dependent and occur in both healthy subjects (El-Sayed et al., 1995) and patients with coronary artery disease (deJong et al., 2006). We previously demonstrated that moderate intervals of recovery $(90 \mathrm{sec})$ with a moderate load (70\% 1RM) increase the anti-inflammatory cytokine interlukin- 6 compared to short intervals of recovery $(30 \mathrm{sec})$
(Rossi et al., 2016), however, it is not known how different recovery intervals influence lipid profile and PAI-1 response in healthy subjects after exhaustive strength exercise.

Thus, the purpose of this study was to investigate the influence of short (30 sec) and moderate (90 sec) recovery intervals on blood lipids and PAI-1 following exhaustive strength exercise in recreational weightlifters. Our hypothesis is that a high-intensity strength exercise session with moderate recovery intervals (90 sec) will improve the acute lipid profile and reduce PAI-1 compared to short recovery intervals $(30 \mathrm{sec})$.

\section{MATERIALS AND METHODS}

\section{Experimental approach to the problem}

To investigate the effect of exhaustive strength exercise with two different rest periods between sets (30 and $90 \mathrm{sec}$ ) on the lipid profile response and fibrinolysis, data was collected using a randomized and counterbalanced within-subjects design. Subjects performed the two exercise sessions separated by $72 \mathrm{hr}$. The test of $1 \mathrm{RM}$ was determined on nonconsecutive days, one week before the exercise protocols for all subjects. Height and total mass were measured with the subjects wearing light clothing on the same morning as the Dual-Energy X-ray Absorptiometry (DXA scan). Blood samples were collected pre exercise, immediately post exercise, and post-15 min and post-30 min into recovery (Fig. 1).

\section{Subjects}

Seven male subjects with strength training experience ( $>6$ months) voluntarily participated in this study. All subjects performed weight training with a mean frequency of four sessions per week, for approximately $1 \mathrm{hr}$ per session. Inclusion criteria for participation in the study were: age between 20 to 32 years; no contraindications involving the cardiovascular system, muscles, joints, or bones of the lower limbs, as regarding the practice of

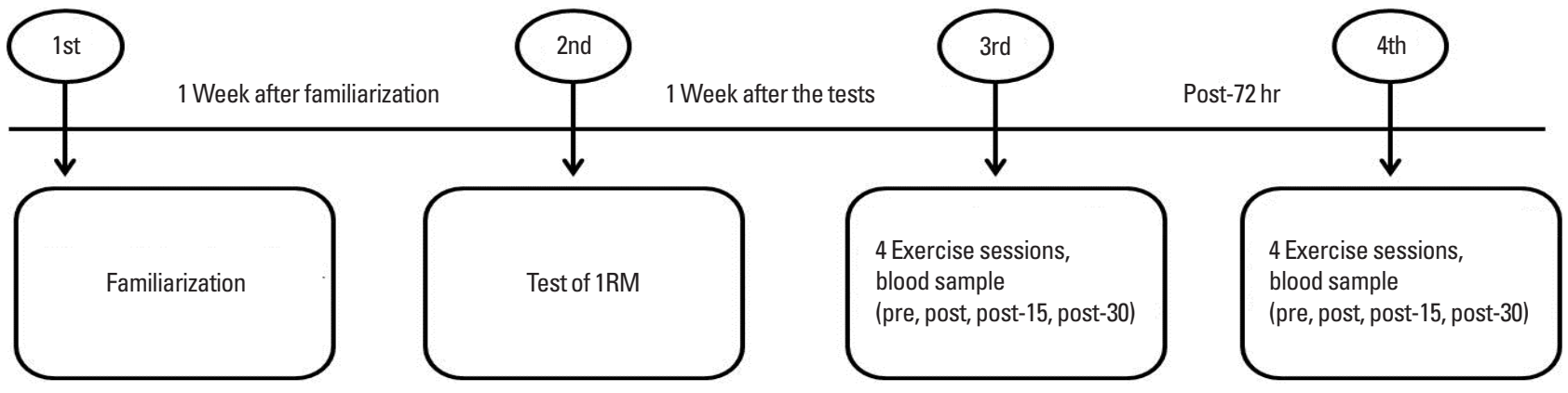

Fig. 1. Study design. 1RM, one maximum repetition. 
strength training. This study was conducted in accordance with the Helsinki Declaration. The project was approved by the Ethics Research Group of the São Paulo State University (Protocol: 2279 3414.7.0000.5402). Informed consent was obtained from all participants.

\section{Anthropometric measurements and dietary intake assessment}

Body weight was measured using an electronic scale (Filizola PL 50, Filizola Ltda., Brazil) with a precision of $0.1 \mathrm{~kg}$. Body composition was estimated using a DXA scanner (Lunar DPX-NT ver. 4.7, GE Healthcare, Buckinghamshire, England). The subjects were positioned in a supine position and remained immobile throughout the examination. FM and FFM were assessed and expressed in percentage values. All measurements were carried out at the University laboratory in a temperature-controlled room. Each morning, before the beginning of the measurements, the equipment was calibrated by the same researcher according to the manufacturer's instructions. Anthropometry consisted of body weight and height measurements. Height was measured on a fixed stadiometer with an accuracy of $0.1 \mathrm{~cm}$ and a length of $2.20 \mathrm{~m}$.

Diet was not standardized; however participants were required to eat three hours prior to all testing sessions. Participants were instructed by a nutritionist how to complete the food records and were required to record all foods consumed on the day of each testing session. Nutrition data was analyzed for energy intake and macronutrient distribution using the NutWin software ver. 1.5 (Programa de Apoio à Nutrição, Universidade Federal de São Paulo, Brazil, 2002).

\section{Test of 1RM}

The 1RM test consisted of a five minutes of warm-up (jogging), followed by the performance of one set of 10 repetitions of each exercise at approximately $50 \%$ of the body mass. The load was increased gradually $(10 \%-15 \%)$ during the test until the participants were no longer able to perform the entire movement, and 3 to $5 \mathrm{~min}$ of recovery were provided between attempts (Miller, 2012). No rest was allowed between the concentric and eccentric phases of the movement, and the participants were encouraged verbally to exert a maximum effort. The test of $1 \mathrm{RM}$ was performed using the squat and bench press exercises. In addition, for better control of the 1RM test procedures, a wooden seat with adjustable heights was placed behind the participant in order to keep the bar displacement and knee angle $\left(\sim 90^{\circ}\right)$ constant on each halfsquat repetition. Two fitness professionals supervised all testing sessions. One week prior to testing the participants performed four sets of 10-12 repetition in each exercise 3 times per week (Monday, Wednesday, and Friday) for familiarization with equipment.

\section{Experimental protocol}

The exercise order for all sessions was squats followed by bench press. In both conditions subjects performed 4 sets of squat and bench press (totaling 8 sets) using $90 \%$ of the 1RM. In the short-interval condition $30 \mathrm{sec}$ (30-sec condition) of rest was allowed between sets and exercises, whereas in the moderate-interval condition $90 \mathrm{sec}$ (90-sec condition) of rest were allowed between sets and exercises. All the sequences of exercises were performed for four sets until movement failure for each exercise with normal speed (1-sec eccentric and 1-sec concentric actions with 1-sec pause between each repetition) (Watanabe et al., 2015).

At $72 \mathrm{hr}$ after the $1 \mathrm{RM}$ test subjects performed two randomized exercise sessions separated by 72 -hr interval. Before the exercise sessions, five minutes of warm-up (jogging) was performed. During the exercise sessions subjects were verbally encouraged to perform all sets until exhaustion in each exercise. The total number of repetitions performed was recorded for each set of each exercise and for all sequences, and used to analyze workload and performance. All the sequences of exercises were performed 3-hr postprandial.

\section{Blood samples and analysis}

Blood samples were collected 3-hr postprandial. The blood samples $(10 \mathrm{~mL})$ were immediately allocated into two $5-\mathrm{mL}$ vacutainer tubes (Becton Dickinson, BD, Juiz de Fora, Brazil) containing ethylenediaminetetraacetic acid for plasma separation and into one $5-\mathrm{mL}$ dry vacutainer tube for serum separation. The tubes were centrifuged at 3,500 rpm for $15 \mathrm{~min}$ at $4^{\circ} \mathrm{C}$, and plasma and serum samples were stored at $-20^{\circ} \mathrm{C}$ until analysis. PAI-1 (0.16-10 $\mathrm{ng} / \mathrm{mL}$ ) was assessed using enzyme-linked immunosorbent assay commercial kits (R\&D Systems, Minneapolis, MN, USA). Total cholesterol (standard $200 \mathrm{mg} / \mathrm{dL}$ ), high-density lipoprotein (standard $20 \mathrm{mg} / \mathrm{dL}$ ), and triacylglycerol (standard $200 \mathrm{mg} / \mathrm{dL}$ ) were assessed using commercial kits (Labtest, São Paulo, Brazil). LDL was calculated according to (Friedewald et al., 1972). To eliminate interassay variance, all samples were analyzed in identical runs.

\section{Statistical analysis}

Data normality was verified using the Shapiro-Wilk test. The comparison of the maximum number of repetitions, food intake and macronutrient between conditions were analyzed using the 
Table 1. General characteristics of the sample $(n=7)$

\begin{tabular}{lcc}
\hline Variable & \multicolumn{2}{c}{ Mean \pm SD } \\
\hline Age (yr) & \multicolumn{3}{c}{$24.6 \pm 4.1$} \\
Height (cm) & \multicolumn{3}{c}{$176.5 \pm 10.1$} \\
Weight (kg) & \multicolumn{3}{c}{$76.1 \pm 8.3$} \\
Fat mass (\%) & \multicolumn{2}{c}{$18.8 \pm 6.4$} \\
Fat free mass (\%) & \multicolumn{3}{c}{$58.2 \pm 6.5$} \\
Dietary intake & $30 \mathrm{sec}$ & $90 \mathrm{sec}$ \\
$\quad$ Total food intake (kcal) & $824.0 \pm 640$ & $935 \pm 532$ \\
Carbohydrates (g) & $125.7 \pm 127.6$ & $134.7 \pm 99.3$ \\
Protein (g) & $43.7 \pm 29.7$ & $40.9 \pm 34.4$ \\
Lipids (g) & $16.3 \pm 9.2$ & $26.3 \pm 11.4$ \\
\hline
\end{tabular}

$\mathrm{SD}$, standard deviation.

Student t-test for independent samples. The differences in lipid profile (Chol, TAG, LDL, HDL-c) and PAI-1 were analyzed via a two-way analysis of variance (condition $\times$ time) with repeated measures. When a significant difference in condition or interaction was observed, a Tukey post hoc test was conducted. For all measured variables, the estimated sphericity was verified according to Mauchly's W test, and the Greenhouse-Geisser correction was used when necessary. Finally, Pearson correlation $(r)$ analyzed the relationship between "mean differences" for PAI-1 concentration in both conditions (Immediately post exercise minus baseline) with "mean differences" for lipids profile across time (immediately postexercise minus baseline; post-15 exercise minus immediately postexercise; and post-30 exercise minus immediately post exercise) and body composition. Statistical significance was set at $P<0.05$. The data were analyzed using the Biostat (version 5.0).

\section{RESULTS}

Table 1 presents the mean values of age, height, weight, percentage of FM, percentage of fat free mass, and total energy intake and macronutrient distribution. There were no statistically significant differences in total food intake and macronutrient distribution between conditions. There were significant differences between condition for performance in bench press (number of repetitions: $30 \mathrm{sec}=8.3 \pm 2.7 \times 90 \mathrm{sec}=14.6 \pm 4.0$ repetition, $P=0.005$ ) and a trend for differences in squat (number of repetitions: $30 \mathrm{sec}=$ $16.7 \pm 7.8 \times 90 \mathrm{sec}=30.4 \pm 14.9$ repetition, $P=0.052$ ).

Table 2 presents the change in lipid profile across time between conditions. There was no main effect of time for LDL-c $(F=1.826$, $P=0.201)$, but there was a trend for differences between conditions $(F=9.645, P=0.053)$. For HDL-c there was no main effect of time $(F=2.539, P=0.096)$ and a statistically significant main
Table 2. Comparison on lipid profile between interval recovery in recreational weightlifters

\begin{tabular}{|c|c|c|c|}
\hline \multirow{2}{*}{ Variable } & \multicolumn{2}{|c|}{ Recovery Intervals } & \multirow{2}{*}{$P$-value } \\
\hline & $30 \mathrm{sec}$ & $90 \mathrm{sec}$ & \\
\hline Chol (mg/dL) & & & 0.440 \\
\hline Pre & $134.0 \pm 45.1$ & $125.4 \pm 43.0$ & \\
\hline Immediately & $137.4 \pm 50.1$ & $131.4 \pm 47.6$ & \\
\hline Post-15 & $138.2 \pm 51.2$ & $135.4 \pm 44.3$ & \\
\hline Post-30 & $135.7 \pm 45.4$ & $167.9 \pm 74.4$ & \\
\hline LDL-c (mg/dL) & & & 0.266 \\
\hline Pre & $82.0 \pm 19.5$ & $75.9 \pm 30.8$ & \\
\hline Immediately & $73.9 \pm 16.4$ & $66.2 \pm 35.5$ & \\
\hline Post-15 & $96.7 \pm 12.9$ & $79.3 \pm 32.0$ & \\
\hline Post-30 & $80.3 \pm 30.2$ & $89.9 \pm 23.5$ & \\
\hline $\mathrm{HDL}-\mathrm{c}(\mathrm{mg} / \mathrm{dL})$ & & & 0.082 \\
\hline Pre & $53.5 \pm 9.2$ & $55.8 \pm 11.1$ & \\
\hline Immediately & $61.4 \pm 11.4$ & $84.9 \pm 27.8$ & \\
\hline Post-15 & $57.8 \pm 8.5$ & $61.8 \pm 9.7$ & \\
\hline Post-30 & $57.5 \pm 7.7$ & $62.1 \pm 20.5$ & \\
\hline TAG (mg/dL) & & & 0.126 \\
\hline Pre & $117.3 \pm 25.4$ & $103.6 \pm 13.1$ & \\
\hline Immediately & $131.1 \pm 37.5$ & $110.4 \pm 12.3$ & \\
\hline Post-15 & $122.1 \pm 31.5$ & $102.9 \pm 13.3$ & \\
\hline Post-30 & $113.3 \pm 21.0$ & $103.7 \pm 11.8$ & \\
\hline Chol/HDL (mg/dL) & & & 0.153 \\
\hline Pre & $2.5 \pm 1.1$ & $2.5 \pm 1.2$ & \\
\hline Immediately & $2.2 \pm 0.7$ & $1.9 \pm 1.2$ & \\
\hline Post-15 & $2.5 \pm 1.1$ & $2.3 \pm 1.0$ & \\
\hline Post-30 & $2.4 \pm 1.0$ & $3.1 \pm 1.6$ & \\
\hline
\end{tabular}

Chol, total cholesterol; HDL-c, high-density lipoprotein cholesterol; LDL-c, low-density lipoprotein cholesterol; TAG, triacylglycerol.

effect was found for condition $(F=21.848, P=0.005)$; however, post hoc analysis found no significant differences between conditions at any time point nor when the data was pooled. There was no main effects of time for the Chol/HDL ratio $(F=1.530, P=$ $0.257)$ nor differences between condition $(F=0.249, P=0.644)$. There were no significant differences between time and condition for Chol and TAG. There were no interactions (condition $\times$ time) for any lipid profile variable.

There were no main effects of time for PAI-1 concentration $(F=0.741, P=0.542)$ nor differences between condition $(F=$ 2.264, $P=0.183$ ), however, a significant interaction was found (time $\times$ condition: $F=3.309, P=0.044$ ) (Fig. 2). PAI-1 decreased immediately postexercise in 90 -sec condition (pre, 7.75 \pm 2.93 ; immediately, 5.31 \pm 4.64; post-15, 6.42 \pm 3.36 ; post-30, $6.6 \pm$ $4.00 \mathrm{ng} / \mathrm{mL} ; P=0.073$ ) but no differences were found for the 30 sec condition (pre, $6.96 \pm 3.55$; immediately, $7.35 \pm 3.04$; post- 


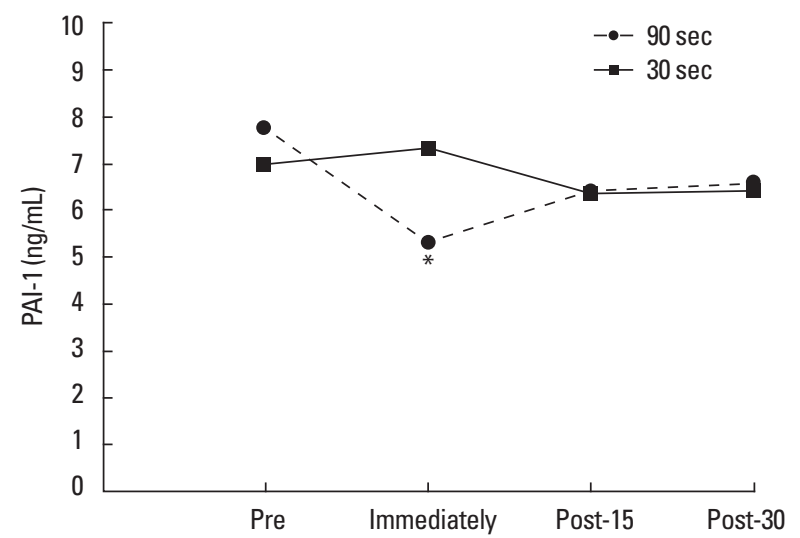

Fig. 2. Comparison on PAI-1 concentration between short and moderate interval recovery in recreational weightlifters. PAl-1, plasminogen activator inhibitor-1. * Statistically significant difference between pre moment.

\section{$15,6.36 \pm 3.7$; post- $30,6.46 \pm 3.45 \mathrm{ng} / \mathrm{mL} ; P=0.303)$.}

Table 3 presents the correlation values between PAI-1, lipid profile and body composition according to condition. For PAI-1 in the 90-sec condition, there was a significant positive stronger correlation with Chol changes immediately post-exercise and 15 min postexercise and LDL 15-min postexercise. There were significant positive correlations between 30-sec condition PAI-1 concentrations and TAG immediately postexercise. In both conditions there significant positive correlations between PAI- 1 and FFM\%. There was no significant correlations between PAI-1 and FM\% in either condition analyzed.

\section{DISCUSSION}

The main findings of the present study was that moderate rest intervals induced a reduction in PAI-1 levels postexercise compared to short rest intervals. Postexercise decreases in PAI-1 levels were strongly correlated to acute decreases in total cholesterol and LDL-c with moderate rest only and with fat free mass percentage in both conditions.

A recent systematic review concluded that strength training promotes an improvement in the lipid profile, especially regarding decreases in LDL-c concentrations (Tambalis et al., 2009), and these positive strength exercise adaptations on the lipoprotein profile seem to occur regardless of obesity status (Roberts and Gerszten, 2013). In the present study HDL-c concentrations were elevated postexercise (in the 90 -sec condition) $(52.2 \%$ ), however this difference did not reach statistical significance. Lira et al. (2010b) investigated four intensities of acute bench press strength exercise $(50 \%, 75 \%, 90 \%$, and $110 \% 1 \mathrm{RM})$ with 2 min of rest between
Table 3. Correlation between PAI-1, lipid profile and body composition according different recovery interval in recreational weightlifters

\begin{tabular}{|c|c|c|}
\hline \multirow{2}{*}{ Variable } & PAl-1 & PAI-1 \\
\hline & $30 \mathrm{sec}$ & $90 \mathrm{sec}$ \\
\hline \multicolumn{3}{|c|}{ Chol (mg/dL- 30 sec) } \\
\hline Immediately & 0.63 & - \\
\hline Post-15 & 0.77 & - \\
\hline Post-30 & 0.75 & - \\
\hline \multicolumn{3}{|c|}{ Chol (mg/dL- 90 sec) } \\
\hline Immediately & - & $0.91 *$ \\
\hline Post-15 & - & $0.84^{*}$ \\
\hline Post-30 & - & 0.14 \\
\hline \multicolumn{3}{|c|}{ LDL-c (mg/dL- $30 \mathrm{sec})$} \\
\hline Immediately & 0.55 & - \\
\hline Post-15 & 0.33 & - \\
\hline Post-30 & 0.68 & - \\
\hline \multicolumn{3}{|c|}{ LDL-c (mg/dll- 90 sec) } \\
\hline Immediately & - & 0.72 \\
\hline Post-15 & - & $0.88^{*}$ \\
\hline Post-30 & - & 0.75 \\
\hline \multicolumn{3}{|c|}{ HDL-c (mg/dL- $30 \mathrm{sec})$} \\
\hline Immediately & 0.28 & - \\
\hline Post-15 & -0.17 & - \\
\hline Post-30 & -0.30 & - \\
\hline \multicolumn{3}{|c|}{$\mathrm{HDL}-\mathrm{c}(\mathrm{mg} / \mathrm{dL}-90 \mathrm{sec})$} \\
\hline Immediately & - & -0.006 \\
\hline Post-15 & - & -0.21 \\
\hline Post-30 & - & -0.26 \\
\hline \multicolumn{3}{|c|}{$\mathrm{TAG}$ (mg/dL- $30 \mathrm{sec}$ ) } \\
\hline Immediately & $0.87^{*}$ & - \\
\hline Post-15 & 0.76 & - \\
\hline Post-30 & 0.78 & - \\
\hline \multicolumn{3}{|c|}{ TAG (mg/dL- 90 sec) } \\
\hline Immediately & - & 0.11 \\
\hline Post-15 & - & 0.51 \\
\hline Post-30 & - & 0.18 \\
\hline \multicolumn{3}{|l|}{ FM\% (baseline) } \\
\hline Immediately & 0.22 & -0.07 \\
\hline Post-15 & -0.26 & -0.07 \\
\hline Post-30 & -0.16 & 0.37 \\
\hline \multicolumn{3}{|c|}{ FFM\% (baseline) } \\
\hline Immediately & 0.74 & $0.77^{*}$ \\
\hline Post-15 & $0.79^{*}$ & $0.81^{*}$ \\
\hline Post-30 & $0.81^{*}$ & 0.68 \\
\hline
\end{tabular}

Chol, total cholesterol; HDL-c, high-density lipoprotein cholesterol; LDL-c, low-density lipoprotein cholesterol; TAG, triacylglycerol; FM\%, percentage of fat mass; FFM $\%$, percentage of fat free mass.

${ }^{*} P<0.05$ 
sets on the lipoprotein profile and reported low (50\% 1RM) and moderate (75\% 1RM) intensities positively modified the lipoprotein profile whereas there were no significant changes following the higher intensity sessions ( $90 \%$ and $110 \% 1 \mathrm{RM}$ ). In our study the greatest number of repetitions were performed with 90 -sec condition of rest, and in Lira et al. (2010b) the greatest number of repetitions were performed with $50 \% 1 \mathrm{RM}$, which translated to the largest increases in HDL-c and decreases in TAG levels. Thus, the results these studies suggest that manipulating intensity and recovery interval to achieve higher overall volumes may be optimal for improving a patient's lipid profile. Reiterating the importance of the present findings, a classical study showed that an incremental increase of $1 \mathrm{mg} / \mathrm{dL}$ in high-density lipoprotein was associated with a significant decrease of coronary heart disease risk of more than $2 \%$, and a reduction of more than $3 \%$ of cardiovascular disease mortality rates, regardless sex (Gordon and Rifkind, 1989).

Improvements in the lipid profile following an acute strength training session may be due to an increase in the reverse cholesterol transport pathway. To the best of our knowledge, only one study has investigated the proteins involved in reverse cholesterol transport after acute strength training. Ghanbari-Niaki et al. (2011) evaluated the response of lipid profile and lymphocyte cholesterol efflux regulatory protein (CERP) expression at three different intensities ( $40 \%, 60 \%$, and $80 \%$ of $1 \mathrm{RM}$ ) with $60 \mathrm{sec}$ of rest period during circuit strength training. They found that $60 \%$ and $80 \% 1 \mathrm{RM}$ intensities improved lipid profile via a decrease in very low-density lipoprotein and atherogenic index. Moreover, all three intensities resulted in an increase of CERP expression in lymphocytes.

PAI-1 both inhibits fibrinolysis and has pleiotropic properties that are upregulated in pathological states, such as metabolic syndrome or chronic inflammation (Iwaki et al. 2012). Fibrin and fibrin degradation products can be localized in the atherosclerotic plaque inducing the fibrinolytic process (Bini et al., 1989), however, higher PAI-1 concentrations demonstrate atherogenic properties by stabilizing fibrin. As such, PAI-1 is associated with a higher incidence of myocardial infarction (Zorio et al., 2008), metabolic syndrome (Garg et al., 2012), sedentary behavior (Lira et al., 2010a) and cancer (Andreasen, 2007).

PAI-1 levels decreased 31.5\% immediately postexercise in the 90-sec condition only. In agreement with these findings, Ahmadizad and El-Sayed (2003) compared three different intensities ( $40 \%, 60 \%$, and $80 \%$ of $1 \mathrm{RM}$ ) with preset repetitions (10, 7 , and 5 , respectively) on platelet aggregation in healthy male subjects during upper and lower body exercise and concluded that only
80\% 1RM increased platelet aggregation and beta-thromboglobulin. The discrepancy between these results and those of Lira et al. (2010b) whereby lower intensities had a more significant impact on PAI-1 levels were likely due to the study design. In Lira et al. (2010b) all sets were taken to momentary muscular failure, whereas in Ahmadizad and El-Sayed (2003) the sets were stopped approximately 15,10 , and 3 , respectively, repetitions prior to predicted momentary muscular failure (Miller, 2012).

Cerneca et al. (1999) investigated the behavior of the coagulation system following near-maximal tests in competitive athletes (marathon runners, rowers, competitive weight lifters, and sedentary controls) on their respected modes of exercises (treadmill, rowing ergometer, loaded barbells, and cycle ergometer, respectively) and found similar increased tPA and decrease PAI-1 levels only after rowing and running. The low volume of the weight lifting tests may explain the lack of significant changes following the resistance training tests. In contrast, deJong et al. (2006) verified the coagulation and fibrinolytic responses after one set of 10 repetitions to volitional fatigue with $60 \mathrm{sec}$ of recovery intervals during eight exercises in patients with coronary artery disease and observed increased tPA and decreased PAI-1 immediate postexercise. Furthermore, the reduction in PAI-1 levels persisted at 1-hr postexercise, showing that strength training seems to positively modulate the fibrinolytic system through increased tPA concentrations and decrease PAI-1 concentrations in both healthy subjects and patients with cardiovascular disease.

We found a positive relationship between lipid profile and PAI1 levels, in that postexercise decreases in PAI-1 were strongly correlated with decreases in total cholesterol and LDL-c only in the 90-sec condition (Table 3). In agreement with our results, Raiko et al. (2012) correlated PAI-1 and lipid profile in 3,596 healthy men and women and observed positive but weak correlations with Chol (men: $r=0.20$ and women: $r=0.13, P<0.001$ ) and TAG (men: $r=0.48$, women: $r=0.32, P<0.001$ ), and a negative correlation with HDL-c (men: $r=-0.25$, women: $r=-0.26$ ). In addition, Garg et al. (2012) compared metabolic syndrome and healthy young adults and found positive associations between PAI-1, body mass index and percentage of FM. De Mitrio et al. (1999) correlated PAI-1, leptin, lipid profile and body composition in nondiabetic women aged 18 to 45 years and observed a positive correlation between PAI-1 and FM $(r=0.33, P<0.001)$, leptin plasma $(r=0.49, P<0.001)$ and FFM $(r=0.33, P<0.01)$. We did not find any significant correlations between PAI-1 levels and percentage of FM, but greater decreases in PAI-1 were correlated with higher lean mass, suggesting that leaner body com- 
positions may positively influence fibrinolysis.

The intervals of recovery used in this study were selected because they represent common rest intervals often employed by strength coaches and personal trainers as well as by competitive and recreational lifters in their practices. Despite the relevance and novelty of these results, it is necessary to mention some limitations; (a) Total volume was not matched between conditions; (b) The small sample size and the training status of the participants (recreational weightlifters) may be have decreased the response on the variables analyzed. If the subject pool was older or at a higher risk of ischemic events there may have been a greater likelihood for changes in PAI-1; (c) In our study only PAI-1 was measured. Measuring tPA in future studies will provide a better understanding of the effects of resistance training variables on coagulation, as some studies observed changes in tPA without statistically significant difference in PAI-1 concentration (Nagelkirk et al., 2010) or relationships between variables (Aziz et al., 2014).

In summary, we conclude that short and moderate intervals of recovery improve acute lipid profile after heavy strength exercise but only 90 sec induced a higher reduction in PAI-1 concentration in recreational weightlifters. Furthermore, there was strong positive correlation between changes PAI-1, lipid profile and percentage of FFM in healthy subjects.

This study demonstrates to coaches, trainers, and clinicians that short $(30 \mathrm{sec})$ and moderate $(90 \mathrm{sec})$ intervals of recovery can be used when the objective of training is to improve lipid profile, however, moderate intervals of recovery seem to induce greater benefits on blood fibrinolysis in healthy subjects, likely due to the greater volume accomplished. Furthermore, resistance training in this fashion may be an effective non-pharmacological strategy in the attenuation of atherosclerosis, thereby reducing prescription medicine requirements during the aging process.

\section{CONFLICT OF INTEREST}

No potential conflict of interest relevant to this article was reported.

\section{REFERENCES}

Ahmadizad S, El-Sayed MS. The effects of graded resistance exercise on platelet aggregation and activation. Med Sci Sports Exerc 2003;35: 1026-1032.

Andreasen PA. PAI-1 - a potential therapeutic target in cancer. Curr Drug Targets 2007;8:1030-1041.
Aziz CB, Omar N, Abdullah WZ, Jalil RA, Nik WS, Zakaria R. Reduced fibrinogen, fibrinolytic biomarkers, and physical parameters after a weight-loss program in obese subjects. N Am J Med Sci 2014;6:377382.

Baynard T, Jacobs HM, Kessler CM, Kanaley JA, Fernhall B. Fibrinolytic markers and vasodilatory capacity following acute exercise among men of differing training status. Eur J Appl Physiol 2007;101:595-602.

Bini A, Fenoglio JJ Jr, Mesa-Tejada R, Kudryk B, Kaplan KL. Identification and distribution of fibrinogen, fibrin, and fibrin(ogen) degradation products in atherosclerosis. Use of monoclonal antibodies. Arteriosclerosis 1989;9:109-121.

Cerneca F, Crocetti G, Gombacci A, Simeone R, Tamaro G, Mangiarotti MA. Variations in hemostatic parameters after near-maximum exercise and specific tests in athletes. J Sports Med Phys Fitness 1999;39:3136.

De Mitrio V, De Pergola G, Vettor R, Marino R, Sciaraffia M, Pagano C, Scaraggi FA, Di Lorenzo L, Giorgino R. Plasma plasminogen activator inhibitor-I is associated with plasma leptin irrespective of body mass index, body FM, and plasma insulin and metabolic parameters in premenopausal women. Metabolism 1999;48:960-964.

deJong AT, Womack CJ, Perrine JA, Franklin BA. Hemostatic responses to resistance training in patients with coronary artery disease. J Cardiopulm Rehabil 2006;26:80-83.

El-Sayed MS, Lin X, Rattu AJ. Blood coagulation and fibrinolysis at rest and in response to maximal exercise before and after a physical conditioning programme. Blood Coagul Fibrinolysis 1995;6:747-752.

Friedewald WT, Levy RI, Fredrickson DS. Estimation of the concentration of low-density lipoprotein cholesterol in plasma, without use of the preparative ultracentrifuge. Clin Chem 1972;18:499-502.

Garg MK, Dutta MK, Mahalle N. Adipokines (adiponectin and plasminogen activator inhhibitor-1) in metabolic syndrome. Indian J Endocrinol Metab 2012;16:116-123.

Ghanbari-Niaki A, Saghebjoo M, Hedayati M. A single session of circuit-resistance exercise effects on human peripheral blood lymphocyte ABCA1 expression and plasma HDL-C level. Regul Pept 2011;166:42-47.

Gordon DJ, Rifkind BM. High-density lipoprotein--the clinical implications of recent studies. N Engl J Med 1989;321:1311-1316.

Iwaki T, Urano T, Umemura K. PAI-1, progress in understanding the clinical problem and its aetiology. Br J Haematol 2012;157:291-298.

Kelley GA, Kelley KS. Effects of aerobic exercise on C-reactive protein, body composition, and maximum oxygen consumption in adults: a meta-analysis of randomized controlled trials. Metabolism 2006;55: 1500-1507.

Kueht ML, McFarlin BK, Lee RE. Severely obese have greater LPS-stimu- 
lated TNF-alpha production than normal weight African-American women. Obesity (Silver Spring) 2009;17:447-451.

Kupchak BR, Creighton BC, Aristizabal JC, Dunn-Lewis C, Volk BM, Ballard KD, Comstock BA, Maresh CM, Kraemer WJ, Volek JS. Beneficial effects of habitual resistance exercise training on coagulation and fibrinolytic responses. Thromb Res 2013;131:e227-234.

Lira FS, Neto JC, Seelaender M. Exercise training as treatment in cancer cachexia. Appl Physiol Nutr Metab 2014;39:679-686.

Lira FS, Rosa JC, Lima-Silva AE, Souza HA, Caperuto EC, Seelaender MC, Damaso AR, Oyama LM, Santos RV. Sedentary subjects have higher PAI-1 and lipoproteins levels than highly trained athletes. Diabetol Metab Syndr 2010a;2:7.

Lira FS, Yamashita AS, Uchida MC, Zanchi NE, Gualano B, Martins E Jr, Caperuto EC, Seelaender M. Low and moderate, rather than high intensity strength exercise induces benefit regarding plasma lipid profile. Diabetol Metab Syndr 2010b;2:31.

Miller T. NSCA's guide to tests and assessments. Champaign (IL): Human Kinetics; 2012.

Nagelkirk PR, Scalzo R, Harber M, Kaminsky LA. The influence of acute resistance training and body composition on coagulation and fibrinolytic activity in low-risk women. Int J Sports Med 2010;31:458-462.

Ouerghi N, Khammassi M, Boukorraa S, Feki M, Kaabachi N, Bouassida A. Effects of a high-intensity intermittent training program on aerobic capacity and lipid profile in trained subjects. Open Access J Sports Med 2014;5:243-248.

Raiko JR, Oikonen M, Wendelin-Saarenhovi M, Siitonen N, Kähönen M, Lehtimäki T, Viikari J, Jula A, Loo BM, Huupponen R, Saarikoski L, Juonala M, Raitakari OT. Plasminogen activator inhitor-1 associates with cardiovascular risk factors in healthy young adults in the Cardiovascular Risk in Young Finns Study. Atherosclerosis 2012;224:208-212.

Roberts LD, Gerszten RE. Toward new biomarkers of cardiometabolic diseases. Cell Metab 2013;18:43-50.

Rosamond W, Flegal K, Furie K, Go A, Greenlund K, Haase N, Hailpern SM, Ho M, Howard V, Kissela B, Kittner S, Lloyd-Jones D, McDermott M, Meigs J, Moy C, Nichol G, O’Donnell C, Roger V, Sorlie P, Steinberger J, Thom T, Wilson M, Hong Y; American Heart Association Statistics Committee and Stroke Statistics Subcommittee. Heart disease and stroke statistics--2008 update: a report from the American Heart Association Statistics Committee and Stroke Statistics Subcommittee. Circulation 2008;117:e25-146.

Rossi FE, Gerosa-Neto J, Zanchi NE, Cholewa JM, Lira FS. Impact of Short and Moderate Rest Intervals on the Acute Immunometabolic Response to Exhaustive Strength Exercise: Part I. J Strength Cond Res 2016;30:1563-1569.

Shannon KA, Shannon RM, Clore JN, Gennings C, Warren BJ, Potteiger JA. Resistance exercise and postprandial lipemia: The dose effect of differing volumes of acute resistance exercise bouts. Metabolism 2005;54:756-763.

Tambalis K, Panagiotakos DB, Kavouras SA, Sidossis LS. Responses of blood lipids to aerobic, resistance, and combined aerobic with resistance exercise training: a systematic review of current evidence. Angiology 2009;60:614-632.

Vaughan DE. PAI-1 and atherothrombosis. J Thromb Haemost 2005;3: 1879-1883.

Watanabe Y, Tanimoto M, Oba N, Sanada K, Miyachi M, Ishii N. Effect of resistance training using bodyweight in the elderly: Comparison of resistance exercise movement between slow and normal speed movement. Geriatr Gerontol Int 2015;15:1270-1277.

Zorio E, Gilabert-Estellés J, España F, Ramón LA, Cosín R, Estellés A. Fibrinolysis: the key to new pathogenetic mechanisms. Curr Med Chem 2008;15:923-929. 